\title{
Obesity in Childhood and Adolescence: a review in the interface between adipocyte physiology and clinical challenges
}

\author{
Antje Körner, Susann Blüher, Thomas Kapellen, Ante Garten, Jürgen Klammt, \\ Jürgen Kratzsch, ${ }^{1}$ Wieland Kiess
}

Hospital for Children and Adolescents, University of Leipzig, Oststr. 21-25, D 04317 Leipzig, Germany, ${ }^{1}$ Institute of Laboratory Medicine, Clinical Chemistry \& Molecular Diagnostics, University of Leipzig, Liebigstrasse 27, 04103 Leipzig, Germany

\begin{abstract}
Body weight is regulated by a feedback loop in which peripheral signals report nutritional information to an integratory center in the brain. The cloning of the ob gene is consistent with this concept and suggests that body fat content in adult rodents is regulated by a negative feedback loop centered in the hypothalamus. In recent years a number of additional signaling molecules secreted by adipose tissue have been discovered. These hormones, named adipocytokines, include resistin, adiponectin and visfatin. Among the adipocytokines, adiponectin is perhaps the most interesting compound for the clinician since low adiponectin serum levels have been found in obese subjects and in particular insulin resistant patients. The definition and diagnosis of obesity in children and adolescents are surprisingly difficult. The level of fatness at which morbidity increases is determined on an acturial basis. In children and adolescents the degree of body fat mass depends upon ethnic background, gender, developmental stage and age. Treatment and prevention of obesity in childhood and adolescence are major challenges for today's health care providers and societies.
\end{abstract}

\section{OBESITY DEFINITION IN CHILDREN}

Direct measurements of body fat content e.g., hydrodensitometry, bioimpedance, or DEXA are useful tools only in scientific studies. Body-mass index (BMI) (weight in kilograms divided by the

\footnotetext{
Address all correspondence to:

Wieland Kiess, MD, Hospital for Children and Adolescents, University of Leipzig, Oststr. 21-25, D 04317 Leipzig, Germany, Tel.: 49-341-9726000, FAX: 49-341-9726009, e-mail:kiw@medizin.uni-leipzig.de

Received 21-09-05, Revised 20-10-05, Accepted 25-10-05
}

square of the height in meters) is easy to calculate and is correlated sufficiently with direct measures of fatness. BMI is therefore frequently used to define obesity clinically. A child with a BMI above the 97th centile in regard to age and gender is considered to be obese. A child with a BMI greater than the 90th but below the 97th centile would be considered to be overweight. In adults, a BMI greater than $28 \mathrm{~kg} / \mathrm{m}^{2}$ is associated with an increased risk of morbidity such as stroke, ischemic heart disease, or type II diabetes mellitus. Adults with a BMI greater 
than $30 \mathrm{~kg} / \mathrm{m}^{2}$ are classified as being obese (grade 2 overweight) while those with a BMI between 25 and $29.9 \mathrm{~kg} / \mathrm{m}^{2}$ are considered to be grade 1 overweight. A BMI over $40 \mathrm{~kg} / \mathrm{m}^{2}$ is classified as grade 3 overweight. A central distribution of body fat is associated with a higher risk of morbidity and mortality in adulthood. ${ }^{1,2}$ The International Obesity Task Force has proposed that the adult body mass index cut-off points $\left(25\right.$ and $\left.30 \mathrm{~kg} / \mathrm{m}^{2}\right)$ should be linked to body mass index percentiles for children to provide for child cut-off points. ${ }^{1-14}$ Besides BMI other nonivasive useful clinical measures of obesity are waist circumference, skin fold thickness and waist-to-hip ratio. Waist circumference and waist-to-hip ratio are helpful to assess upper body fat deposition but not provide for measuring visceral-intra-abdominal fat accumulation.

\section{EPIDEMIOLOGY}

Projected obesity rates for obesity (BMI $>30 \mathrm{~kg} /$ $\mathrm{m}^{2}$ ) in the adult population of the United States are $20 \%$ for the year $2000,30 \%$ for the year 2015 , and over $40 \%$ for the year $2025 .^{15,16}$ There is a large increase in BMI in the cohorts with a BMI greater than the 50th percentile. Furthermore, over time, obese children have a tendency towards even more excessive weight. It has become clear that childhood obesity has reached epidemic proportions in all industralised countries. ${ }^{14}$ The current age-adjusted prevalence may be as high as $20-30 \%$. In 1999, in a cross-sectional study in the city of Leipzig, Germany, involving more than 2500 children and adolescents between 7 years and 18 years of age, $29 \%$ of the subjects were overweight (BMI between 90th and 97 th centile, and $16 \%$ were obese (BMI above 97 th centile). In the same geographical area a large population-based study revealed an incidence of obesity in children and adolescents of around $12 \% .{ }^{17}$

\section{ADIPOCYTE ENDOCRINOLOGY}

The discovery of leptin in 1994 opened up a whole field of studies into the biology of adipocytes, their metabolic and endocrine function, and the functional relationships between secretagogues of adipocytes, the so-called adipocytokines, and peripheral metabolic functions. ${ }^{3,4}$ It is now acknowledged that the sequelae of obesity, particularly diabetes and cardiovascular disease, are influenced to a great extent by the actions of these adipocytokines and that the adipose tissue directly contributes to the pathogenesis of obesity related disorders.

The biology of leptin has been intensely studied, even though the relevance of leptin as an anti-obesity hormone has not been proven at least for humans. ${ }^{18}$ Resistin was discovered more recently and has generated a good deal of controversy over its function and relevance for humans, and even about its expression by adipocytes. The most coherent effects have been shown for adiponectin, which reveal adiponectin to be the most promising of the adipocytokines with potential impact for the development of therapeutic strategies. However, many other factors derived from the adipose tissue have been discovered, some of them known, such as the cytokines Il-6 or TNFalpha as well as visfatin, a newly discovered product of visceral fat tissue.

\section{LEPTIN}

The cloning of the ob gene has greatly advanced our understanding of the mechanism underlying adiposity, eating disorders and reproduction. ${ }^{3}$ Leptin, a 167-amino acid containing gene product, demonstrates structural similarities with the cytokine family and is mainly produced by the adipocytes. However, recent studies have confirmed that other tissues also express leptin, including placenta, ovaries, skeletal muscle, stomach, pituitary, and liver. ${ }^{18}$ Leptin acts as an afferent satiety signal regulating appetite and weight in both humans and rodents. It affects central circuits in the hypothalamus, thereby suppressing food intake and stimulating energy expenditure. Thus, leptin plays a major role in the control of body fat stores through coordinated regulation of feeding behaviour, metabolism, the autonomic nervous system, and body energy balance. More recent studies revealed direct effects of leptin on the periphery, in part through interactions with other, peripherally acting, hormones such as insulin.

The leptin receptor (Ob-R) is a large single membrane spanning protein and belongs to the gp 130 family of cytokine class I receptors. In mice, at least six alternatively spliced isoforms (OB-Ra,-Rb,-Rc,- 
$\mathrm{Rd},-\mathrm{Re},-\mathrm{Rf})$ have been identified, all of which are products of the single ob-r gene. ${ }^{4}$ There are four known isoforms of the human leptin receptor with different C-terminal cytoplasmatic domains designated by the number of their unique c-terminal amino acids OB-R5, 15, -67, 274. All these isoforms have identical extracellular ligand binding domains but differ at the intracellular carboxy terminus. In all species OB-R isoforms can be divided into the three classes: long, short, and soluble isoforms. ${ }^{19,20}$ The long isoform OB-Rb is considered to be the major signaling isoform since it is the only isoform that can transmit the leptin signal via the complete JAK-STAT pathway (janus kinase 2 and the activators of transcription STAT 3,5 and 6). ${ }^{21} \mathrm{OB}-\mathrm{Rb}$ is expressed throughout the body and has been located in the hypothalamus, monocytes, lymphocytes, pancreatic beta cells, enterocytes, endothelial, smooth muscle, and other cell types.

Besides the above-mentioned neuroendocrine effects of leptin on the control of food intake and energy expenditure, binding of this hormone has been proved in lung, intestine, kidney, liver, skin, stomach, heart, spleen as well as in other organs, suggesting its apheliotropic actions. These include, for example, the implication of leptin in directly regulating immune cells, pancreatic beta cells, adipocytes, muscle, and blood cells. Leptin appears to act as an endocrine and paracrine factor for the regulation of puberty and reproduction, it affects maternal, placental and fetal function, modifies insulin sensitivity in the muscle or liver, prevents ectopic lipid deposition, and links the endocrine and immune system in the context of skin repair. ${ }^{22}$ The marked effects of leptin on energy homeostasis prompted an approach involving the use of leptin to treat obese individuals, that was, however, disappointing in that body weight reduction was only achieved in a marginal subset of obese patients. ${ }^{23}$ Leptin gene expression is regulated in the context of hormonal and nutritional status. The level of ob mRNA in white adipose tissue and the circulating leptin level are closely associated with the amount of fat mass, as shown in human and rodent studies. Serum leptin levels are significantly higher in females compared to males, after correcting for total body fat, and exhibit a significant $24 \mathrm{~h}$-pattern, with a nocturnal maximum that is not accompanied by commensurate levels in cerebrospinal fluid. Plasma leptin levels are markedly lowered by fasting or dieting and rapidly recovered during refeeding. Leptin expression may also be increased by the actions of insulin, glucose, estrogens, glucocorticoids, TNFalpha, interleukin-1 as well as by conditions of impaired renal function and acute inflammation. A decrease of leptin levels is observed especially in response to beta-adrenoceptor agonists, androgens, cold exposure, thiazolidinediones, and cigarette smoking.

In humans, leptin is encoded by a gene located in chromosome 7q31.3. Congenital leptin deficiency is a rare cause of early onset obesity. To date, only four families with disrupting leptin gene mutations have been identified, three of them of Pakistani origin. Four of the affected children were subjected to recombinant leptin therapy. In all cases this resulted in a dramatic reversal of the phenotype of hyperphagia accompanied by hyperinsulinemia, hyperlipidemia, and other metabolic, neuroendocrine, and immune dysfunctions. Unlike in common obesity, leptin treatment of three leptin deficient adults lead to an average weight loss of $18 \mathrm{~kg}$, accompanied by a $58 \%$ reduction in energy intake and an increase in $62 \%$ in 24-hour fat oxidation in these patients. DNA polymorphisms in the ob gene may be linked to obesity. Sequence variants located in the 5' flanking region of ob gene were found to be associated with obesity or with BMI reduction following a low calorie diet. ${ }^{24,25}$ Gene variants have also been observed for the human leptin receptor. ${ }^{25-}$ ${ }^{27}$ A homozygous mutation creating a donor splice site in exon 16 of the ob-r gene and resulting in a truncated leptin receptor lacking both the transmembrane and the intracellular domain has been detected in a consanguineous French family of Karibian origin. Patients with this mutation demonstrated early onset morbid obesity, no pubertal development, and a reduced secretion of $\mathrm{hGH}$ and $\mathrm{TSH} .{ }^{25}$ The association between other sequence variations of ob-r and obesity remains controversial in humans. A number of studies now provide evidence that leptin is involved in the pathogenesis of atherosclerotic vascular disease. 
In summary, leptin was initially identified as an adipose secretagogue in rodents, that regulates body weight by reporting energy status to the integratory center in the hypothalamus where, consequently, food intake is inhibited. ${ }^{1}$ In humans, the situation is different and the weight reducing effects of leptin are not as pronounced. In addition, the biologic role of the circulating leptin receptor/binding protein has not as yet been elucidated. ${ }^{28-33}$ However, many new peripheral actions of leptin have been discovered, underlining that leptin also plays a role in modulating metabolism, energy expenditure, and pathologic processes in humans. ${ }^{34-37}$

\section{RESISTIN}

Resistin, as a novel adipocyte secreted factor with impact on insulin sensitivity, was proposed as a new mechanism to explain the pathogenic sequence adipocyte-obesity-insulin resistance. ${ }^{38}$ So far, many aspects of the resistin biology as regards to biological effects and regulation are controversial, and the role of resistin as a mediator of insulin resistance, at least in humans, is questionable. On the other hand, current studies provide evidence for a role of resistin in inflammatory processes, that may be involved in atherosclerosis and thus of relevance also in humans, even though the biology markedly differs between species. ${ }^{39-48}$ Resistin has been independently discovered by three groups through exploitation of different experimental approaches aiming to identify targets of thiazolidinediones, to identify adipose secreted factors by microarray, or as a homolog of inflammatory proteins. Current nomenclature refers to the protein as resistin, and the gene as retn, even though ADSF (adipocyte-specific secretory factor) and FIZZ3 (found in inflammatory zone) are used synonymously. Resistin is a 12.5 $\mathrm{kDa}$ cystein-rich peptide that belongs to a family of resistin-like molecules (RELMs) with distinct expression patterns and biological effects. The human peptide consists of 114 amino acids, including a 17 amino acid signal peptide, a variable region of 37 amino acids, and a conserved $\mathrm{C}$-terminus. In all but on pertinent studies in humans was found that resistin is not expressed by adipocytes, but high levels of expression and secretion were localized to bone marrow and peripheral mononuclear cells, with low- er expression in lung, placental tissue, or pancreatic beta-cells. ${ }^{39,41}$ Serum resistin levels were found to be elevated in rodent models of obesity such as ob/ob, db/db-mice, or diet-induced obesity, while other and more recent studies found resistin expression and secretion decreased in a variety of obese rodent models. There is slightly more consistent evidence of increased resistin expression associated with insulin resistance in rodents, ${ }^{43,45}$ pointing towards a potential role of resistin in obesity associated insulin resistance.

However, the putative involvement of resistin in obesity and/or insulin resistance in humans is largely controversial. While some studies report positive correlations between resistin and obesity or insulin resistance, others do not find any relationship. ${ }^{43,45}$ The physiological range of serum resistin levels have so far not been characterized, making interpretation of clinical studies difficult. ${ }^{40}$ When interpretating data from clinical studies, one needs to consider that resistin may occur in different isoforms that could be differentially detected by the various immunoassays currently applied.

To evaluate biological effects of a compound on the whole organism, experimental animal models are a valuable tool and provide a more detailed insight into resistin biology. Abolishing the resistin gene in mice did not, surprisingly, result in profound phenotypic alterations. ${ }^{38}$ Knockout mice had elevated fasting glucose levels but normal glucose tolerance and insulin sensitivity, that were only disturbed when mice were fed a high-fat diet. Chronic elevation of resistin expression and serum levels was achieved by targeted overexpression of resistin in adipose tissue, by implantation of transfected 3T3L1 cells into nude mice, or by adenovirus mediated chronic overexpression. All these models uniformly show a significantly impaired glucose tolerance and insulin signaling along with hyperinsulinemia and dyslipidemia. Hence, at least in rodents, a role of resistin in mediating insulin resistance syndromes appears feasible. Even though the physiologic and pathophysiologic role of resistin for obesity related insulin resistance in humans is not as evident as it is in the mouse emerging concepts suggest a role for resistin in inflammatory states in humans, which correspond to the predominant expression of resis- 
tin by mononuclear cells..$^{38,39,46,47}$

\section{ADIPONECTIN}

The discovery of adiponectin dates back to about the same time as the identification of leptin in 1995/ 1996, but this adipocytokine did not achieve widespread attention in the scientific community for some years, until its markedly protective role in the pathogenesis of obesity-related disorders was acknowledged. ${ }^{10,49}$ Compared to the aforementioned factors, adiponectin differs in almost all of the biological properties and effects. Nevertheless, so far it has proved the most promising adipocytokine with substantial potential for developing novel intervention strategies for obesity related disorders. Four groups independently identified adiponectin as an adipocyte specific factor that is specifically and abundantly expressed and secreted by adipose tissue. Hence, the nomenclature differed initially with GBP28 (gelatine binding protein 28), ACRP (adipocyte complement related protein), apM1 (AdiPose Most abundant Gene transcript 1), and AdipoQ, now, however, commonly referred to as adiponectin. Structurally, adiponectin belongs to the collagen superfamily, sharing homologies with collagens, complement factors, as well as TNF-alpha. The $30 \mathrm{kDa}$ monomer protein of 247 amino acids consists of a hypervariable region following the signal sequence, a collagen-like domain that is important for building secondary and tertiary structure, and a C-terminal globular domain that is responsible for mediating adiponectin effects. ${ }^{7,810}$ Monomeric subunits oligomerize to trimers that further associate through disulphide bonds within the collagenous domain to form bouquet-like polymeric complexes of higher structure including hexameres of app. 180 $\mathrm{kDa}$ (low-molecular weight, LMW), and high-molecular weight $16-18$ polymers of $400-600 \mathrm{kDa}$ (HMW). These higher order complexes are the predominant forms in human serum. The isoforms differ in their biological function, possibly dependent upon the tissue and receptor isotype.$^{50,52,53}$ The trimers appeared to confer increased bioactivity, which may suggest that polymers constitute precursors. Only hexameric and higher complexes, however, were shown to be capable of activating the NF-kB transcription factor, suggesting that oligomerization of adiponectin is essential for at least some of its biological effects. ${ }^{51}$

Adiponectin is exclusively expressed by mature adipocytes with increasing expression and secretion during the process of adipocyte differentiation with higher adiponectin mRNA and protein expression in subcutaneous compared to visceral fat. It occurs in remarkably high concentrations in human blood, of about $10 \mu \mathrm{g} / \mathrm{mL}$, accounting for $0.01 \%$ of total serum protein. Males have significantly lower plasma adiponectin levels than females, this sexual dimorphism developing during pubertal development, in relation to serum androgens. ${ }^{11}$ Even though adiponectin is exclusively synthesized by adipocytes, adiponectin levels are decreased in obesity, in conditions of insulin resistance and diabetes, and in cardiovascular disease with increasing severity. ${ }^{9}$ This reduction in adiponectin appears to precede the disorders, and low adiponectin levels have even been shown to predict the development of type 2 diabetes and cardiovascular disease. ${ }^{52-57}$

Hence, in summary, these clinical-epidemiological studies and animal studies show uniformly a decrease of adiponectin in obesity, and demonstrate that decreased adiponectin levels, even regardless of body fat mass, confer a substantially increased risk for diabetes and cardiovascular disease, suggesting that adiponectin may even directly contribute to the pathogenesis of these diseases.

The adiponectin receptors were initially identified predominantly on muscle cells (AdipoR1) and liver cells (Adipor2), although in humans they are obviously expressed ubiquitously in the body. Globular and full-length adiponectin bind to both receptors and mediate activation of AMP kinase, PPAR $\alpha$ activation, and consequently glucose uptake and fatty-acid oxidation. In the muscle, AdipoR1 was shown to interact with the insulin receptor, thereby enhancing insulin signal transduction, which was one proposed mechanism of adiponectin to ameliorate insulin resistance. In addition, glucose uptake into by the cell is facilitated by stimulated expression of glucose transporter-4, further contributing to insulin sensitivity. ${ }^{55-57}$

In summary, several lines of evidence, consisting of clinical association studies in humans, genet- 
ic studies, experimental animal studies and models, and in vitro studies, impressively and uniformly support the protective role of adiponectin in the development of obesity related disorders and the metabolic syndrome, particularly in the pathogenesis of type 2 diabetes and cardiovascular disease. Research has expanded to include a role for adiponectin in cancer and other disease areas. The development of adiponectin analogs holds great promise for the clinical use in improving insulin sensitivity and preventing atherosclerotic disease.

\section{VISFATIN}

A 'new' adipocytokine was isolated by Fukuhara et al. in $2004 .^{58}$ This adipocytokine, named 'visfatin', was found to be highly enriched in the visceral adipose tissue of both humans and rodents. Visfatin was found to be identical to the previously known pre-B cell colony enhancing factor (PBEF), a cytokine expressed by lymphocytes. Visfatin has a molecular weight of $52 \mathrm{kDa}$. The coding region of the gene encodes for 491 amino acids. When given to mice, visfatin was capable of lowering blood glucose, ${ }^{58}$ this effect again resembling the effects of insulin. In vitro, it was found to mimic insulin action as evidenced by phosphorylation of the insulin receptor, insulin receptor substrates (IRS-1 and IRS2), and the binding of phosphatidyl-inositol-3-kinase (PI3K) to IRS- 1 and IRS-2. In 3T3-F442A adipocytes, visfatin also lead to phosphorylation and activation of Akt and MAP kinases in these cells. Apparently visfatin is able to directly interact with the insulin receptor, though the exact mechanisms of this interaction remain unknown at present. The binding equilibrium dissociation constant of visfatin to the insulin receptor in human embryonic kidney (HEK) -293 cells $(4.4 \mathrm{nM})$ was similar to that of insulin $(6.1 \mathrm{nM})$. In contrast, visfatin did not bind to the insulin-like growth factor-1 receptor. Taking together all the available data, it seems that visfatin activates the insulin receptor signaling cascade, but in a manner distinct from than of insulin. Further study of this natural insulin-mimetic should help to determine its role in maintaining normal glucose homeostasis in humans. ${ }^{59}$

\section{AETIOPATHOGENESIS}

As outlined above, using the physiology of adipocytes and adipocytokines a great deal of knowledge has been accumulated as to the pathogenetic mechanisms of obesity and its co-morbidity. Multiple factors are related to the high incidence of childhood obesity. Both genetic/endogenous and environmental/exogenous factors contribute to the development of a high degree of body fatness early in life (Table 1 and Table 2). ${ }^{60-64}$ Twin studies suggest that at least $50 \%$ of the tendency toward obesity is inherited. There is also increasing evidence that responsiveness to dietary intervention is genetically determined.

Although a number of monogenetic traits that cause childhood obesity have been identified, in general, a multifactorial aetiopathogenesis of obesity will be present in most patients. Exogenous factors, such as overconsumption of fat-rich diets, lack of physical activity allied with excessive hours of TV watching and computer usage (sedentary lifestyle) heavily contribute to the development of obesity. Nutrition and diet early in infancy is thought to influence growth rate and body fatness beyond infancy. Taking the available data together, many authors support a model in which susceptibilty to obesity is determined by genetic factors, but the environment determines individual phenotypic expression.

Table 1. Factors which contribute to the development of obesity.

\section{Genetic factors}

- Possibly polymorphisms and/or mutations in any of the following: adrenergic receptors, leptin, Ob-R, SOCS-3, TNF, POMC, MCH, MC4R, NPY, NPY receptors, CRH, CRH receptors, TRH, urocortin, orexin $\mathrm{A}$ and $\mathrm{B}$, galanin, neurotensin, serotonin, prohormone convertase and and many others

\section{Environmental}

- Increase of sedate activities (TV viewing)

- Lack of and decrease in physical activity

- Shift in diet towards more fast/prepackaged foods with high fat/calory content and/or high sugar content

- Loneliness and social isolation

- Urbanization, housing

- Psychosocial/family problems 
Table 2. Disorders which can present with obesity in childhood differential diagnosis of obesity disorders.

Endocrine disorders
Cushing's syndrome
hypothyroidism
growth hormone deficiency
hyperinsulinemia
(pseudo)hypoparathyroidism (Albright's hereditary dystrophy)
Central nervous system disorders/brain damage
hypothalamic tumor
surgery
trauma
post-inflammation
post-chemotherapy
Genetic syndromes
Prader-Labhard-Willi syndrome
Alstrom syndrome
Bardet Biedl syndrome
Carpenter syndrome
Cohen syndrome
Primary (simple/'exogenous') obesity
(multifactorial, multigenetic susceptibility)

\section{CO-MORBIDITY}

Among the most common sequelae of primary childhood obesity are hypertension, dyslipidemia, and psychosocial problems. A more complete list of co-morbidity disorders is shown in Table 3. These disorders which arise from overweight and subsequent biochemical changes actually predispose for still additional co-morbidity, such as cardiovascular disease in early adulthood. Since approximately 60 $85 \%$ of obese children of school age will continue to be obese in adulthood, the co-morbidity factor represents a major health burden in industrialised societies. In addition, childhood obesity seems to increase the risk of subsequent morbidity whether or not obesity persists in adulthood. Most importantly, type 2 diabetes is being increasingly identified in children and adolescents. The clinical picture in children with type 2 diabetes and the fact that most affected patients come from families with type 2 diabetes mellitus have led physicians to conclude that affected children will respond to the same treatments used in adults and that clinical courses

Table 3. Co-morbidities of obesity in childhood and adolescence. Psychosocial - psychiatric poor self-image, social isolation, autoaggression, suicide, promiscuity, drug and alcohol addiction, bulimia,

binge eating, smoking, (enuresis)

Cardiovascular and respiratory accelerated atherosclerosis, hypertension hypoventilation, sleep apnea, snoring

Pickwickier syndrome reduced lung capacity

Endocrine and metabolic

hyperinsulinemia, insulin resistance, type 2 diabetes mellitus, early puberty, polycystic ovaries, dysmenorrhea dyslipidemia,

Orthopedic slipped capital femoral epiphyses, coxa vara, Blount's disease, Legg-Calve-Perthes disease back pain

Others

paronychia, akanthosis nigricans,

striae rubrae 
will be similar to those described in adults. ${ }^{1,2,16,17}$

\section{THERAPEUTIC APPROACHES}

Because obesity is a risk factor for numerous medical disorders, psychosocial problems, and excess mortality, it is indeed imperative that effective treatment be developed and be widely available and instigated. ${ }^{65-67}$ Therapeutic strategies include psychological and family therapy interventions, lifestyle/ behavior modification and nutrition education. The role of regular exercise and exercise programs is emphasized.

Multidisciplinary outpatient treatments are considered to be the most effective. In most countries, networking of primary care physicians, public health/ school medicine institutions, specialists of paediatric and adolescent medicine, social workers, child psychologists and dietitions as well as sports educators could be instituted. Health insurance providers and policy makers should support such networking concepts. Some workers have reported high success rates in the use of such approaches, as well as, sufficient longterm weight reduction in small groups of children studied.

Since the efficacy of the available treatment strategies is still limited, longterm treatment including extended pharmacotherapy may be necessary for the majority of very obese adolescents. ${ }^{15,65}$ At the present time, two drugs are increasingly being employed (orlistat and sibutramine). Orlistat binds to gastrointestinal lipases and causes a partial inhibition of fat resorption from the gut. In contrast, sibutramine causes a centrally mediated increase in satiety and energy expenditure. When combined with a hypocaloric diet, both drugs lead to a moderate additional weight loss of some kilograms within six months.

It is important to note that appetite suppressants and thermogenic drugs have not been approved for use in children. If one is to classify the agents under development according to their main mode of action, there are three main modes to be distinguished, namely, substances that act upon energy intake, energy storage, or energy output. Agents which influence energy intake may either act through the brain by modifying behaviour or be anorexic. In addition, some agents that reduce energy intake exert their actions by altering gastric emptying, causing malabsorption or relay satiety back to the brain. Drugs that modify energy storage either decrease lipid storage or increase lipid oxidation in the fat tissue. Lastly, energy output can be regulated either in the brain or in skeletal muscle and brown adipose tissues.

It is clear that all therapies must be considered within the framework of a multidisciplinary approach with the support of an interdisciplinary team, which has to include paediatricians/internists, psychologists and dietitians. ${ }^{2,14}$

Children with type 2 diabetes will have to be transitioned to oral antidiabetic agents. Little is known about therapy in children with co-morbid conditions which frequently accompany type 2 diabetes mellitus. Very recently, a multicenter trial of metformin use in children with type 2 diabetes mellitus was completed in the United States. Since metformin also seems to reduce appetite in obese children with type 2 diabetes, it may be beneficial and prove to be the drug of choice in the long term. Side effects include gastrointestinal problems and should not be neglected. ${ }^{17}$

\section{Childhood obesity as a major burden for the economy}

The financial burden of childhood obesity for industrialized societies can only be roughly estimated. The annual economic costs due to medical expenses and lost income as a result of complications of adult obesity is approximately 70 billion dollars in the USA. At least another 30 billion dollars are thought to be spent on diet foods, products and programs to lose weight. If one is to calculate the prospective costs of obesity forms that have started at an early age, the prospective financial costs are even higher. Meanwhile, the sales and profits of the obesity treatment industry have reached astronomic proportions. Therefore, obesity in childhood and adolescence has already become a major factor in health care planning systems and within the health care industry as such. Since obesity is associated with a significant increase in morbidity and mortality, it is a major public health burden. Moreover, in addition to the prospect of diminished health, obese peo- 
ple are often stigmatized both socially and in the workplace. This fact also contributes to the economic cost of obesity, albeit in an unknown and largely indeterminable way. The optimal BMI associated with the greatest longevity is 23 to 25 for whites and 23 to 30 for black adults. For any given degree of overweight, younger people generally have a greater degree of years of life lost than have older subjects. $^{66,67}$

\section{PREVENTION}

As prevention has to start very early in life, a population and community scheme for prevention seems to be the most promising and reasonable approach. However, primary prevention has been proven to be difficult or virtually impossible in most societies. Again a multidisciplinary team approach is called for to develop and secure preventive strategies. Good nutrition and modest exercise for pregnant women as well as monitoring of intrauterine growth of the child must be mandatory. After birth, rapid weight gain should be avoided and principles of good nutrition and physical activities should be taught at all ages. Breast feeding should be strongly recommended. Children's food choices can be influenced by early intervention and guidance. Parents should thus be encouraged to make healthy foods easily available to the child and serve these foods in positive mealtime situations in order to help their child develop healthy food habits. Joint actions by physicians, health authorities and polititians both in the community and also using modern media and mass media are being called upon to implement nation-wide prevention programs. Such programs have to take into account cultural and racial preferences and attitudes in respect to food preparation and eating habits. Taxes on fast foods and soft drinks should be considered, while nutritious foods such as fruits and vegetables could be subsidised for the poorer income classes. Nutrition labels should be required on fast-food packaging. Last but not least, food advertising and marketing directed at children should be banned, while funding for public-health campaigns for obesity prevention should be increased. Recent changes in federal tax laws in the United States may influence health plan roles in promoting physical activity and thus may assist pre- vention of obesity. ${ }^{2,14}$

\section{CONCLUSION}

It is now well known that obesity is the most common chronic disorder in industrialized societies. In some countries, the prevalence of obesity in childhood and adolescence has become higher than that of both asthma and eczema. Childhood obesity is associated with substantial co-morbidity and late sequelae. While diagnostic strategies are clear and straightforward, treatment remains difficult and frustrating both for the patient, family and the multidisciplinary team caring for children with obesity. In our opinion, much more attention should be paid to prevention and the development of preventive strategies at all ages. Prevention should in any case start very early in life. New drugs are being developed that promise to be useful for treatment and secondary prevention. However, sufficient data are not yet available for the use of such agents in childhood and adolescence. Finally, public awareness of the ever-increasing health burden and economic dimension of the childhood obesity epidemic has to be considered by both the public and policy decision makers.

\section{REFERENCES}

1. Friedman JM, 2000 Obesity in the new millenium. Nature 404: 632-634.

2. Kiess W, Galler A, Reich A, et al, 2001 Clinical aspects of obesity in childhood and adolescence. Obesity Reviews 2:29-36.

3. Zhang Y, Proenca R, Maffei M, et al, 1994 Positional cloning of the mouse obese gene and its human homologue. Nature 372: 425-432.

4. Kershaw EE, Flier JS, 2004 Adipose tissue as an endocrine organ. J Clin Endocrinol Metab 89: 2548-2556.

5. Shuldiner AR, Yang R, Gong DW, 2001 Resistin, obesity and insulin resistance - the emerging role of the adipocyte as an endocrine organ. N Engl J Med 345: 1345-1346.

6. Steppan CM, Bailey ST, Bhat S, et al. 2001 The hormone resistin links obesity to diabetes. Nature 409: 307312.

7. Hu E, Liang P, Spiegelman BM, 1996 AdipoQ is a novel adipose-specific gene dysregulated in obesity. J Biol Chem 271: 10697-10703.

8. Trujillo ME, Scherer PE, 2005 Adiponectin - journey from an adipocyte secretory protein to biomarker of 
the metabolic syndrome. J Intern Med 257: 167-175.

9. Böttner A, Wabitsch M, Kratzsch J, et al, 2005 Adiponectin expression is dependent on differentiation of adipocytes. Biochem Biophys Res Commun (in press).

10. Matsuzawa Y, Funahashi T, Kihara S, et al, 2004 Adiponectin and metabolic syndrome. Arterioscler Thromb Vasc Biol 24: 29-33.

11. Böttner A, Kratzsch J, Müller G, et al, 2004 Gender differences of adiponectin levels develop during the progression of puberty and are related to serum androgen levels. J Clin Endocrinol Metab 89: 4053-4061.

12. Spranger J, Kroke A, Mohlig M, et al, 2003 Adiponectin and protection against type 2 diabetes mellitus. Lancet 361: 226-228.

13. Vasseur F, Lepretre F, Lacquemant C, et al, 2003 The genetics of adiponectin. Curr Diab Rep 3: 151-158.

14. Ebbeling CB, Pawlak DB, Ludwig DS, 2002 Childhood obesity: public-health crisis, common sense cure. Lancet 360: 473-482.

15. Manson JE, Bassuk SS, 2003 Obesity in the United States - a fresh look at ist high toll. JAMA 289: 229230.

16. Bray GA, Tartaglia LA, 2000 Medical strategies in the treatment of obesity. Nature 404: 672-677.

17. Kiess W, Böttner A, Raile K, et al, 2003 Type 2 diabetes mellitus in children and adolescents: a review from a European perspective. Horm Res 59: Suppl 1: 77-84.

18. Muoio DM, Lynis DG, 2002 Peripheral metabolic actions of leptin. Best Pract Res Clin Endocrinol Metab 16: 653-666.

19. Lee GH, Proenca R, Montez JM, et al, 1996 Abnormal splicing of the leptin receptor in diabetic mice. Nature 379: 632-635.

20. Barr VA, Lane K, Taylor SI, 1999 Subcellular localization and internalization of the four human leptin receptor isoforms. J Biol Chem 274: 21416-21424.

21. Bjorbaek C, Uotani S, da Silva B, et al, 1997 Divergent signaling capacities of the long and short isoforms of the leptin receptor. J Biol Chem 272: 32686-32695.

22. Bjorbaek C, Kahn BB, 2004 Leptin signaling in the central nervous system and the periphery. Recent Prog Horm Res 59: 305-331.

23. Banks WA, 2004 The many lives of leptin. Peptides 25: 331-338.

24. Considine RV, Sinha MK, Heiman ML, et al, 1996 Serum immunoreactive-leptin concentrations in normal-weight and obese humans. N Engl J Med 334: 292295.

24a.Li WD, Reed DR, Lee JH, et al, 1999 Sequence variants in the 5' flanking region of the leptin gene are associated with obesity in women. Ann Hum Genet 63: 227-234.

25. Clement K, Vaisse C, Lahlou N, et al, 1998 A mutation in the human leptin receptor gene causes obesity and pituitary dysfunction. Nature 392: 398-401.
26. Bjorbaek C, El Haschimi K, Frantz JD, et al, 1999 The role of SOCS-3 in leptin signaling and leptin resistance. J Biol Chem 274: 30059-30065.

27. Munzberg H, Myers MG Jr, 2005 Molecular and anatomical determinants of central leptin resistance. Nat Neurosci 8: 566-570.

28. Lammert A, Kiess W, Böttner A, et al, 2001 Soluble leptin receptor represents the main leptin binding activity in human blood. Biochem Biophys Res Commun 283: 982-988.

29. Huang L, Wang Z, Li C, 2001 Modulation of circulating leptin levels by its soluble receptor. J Biol Chem 276: 6343-6349.

30. Sinha MK, Opentanova I, Ohannesian JP, et al, 1996 Evidence of free and bound leptin in human circulation. Studies in lean and obese subjects and during short-term fasting. J Clin Invest 98: 1277-1282.

31. Kratzsch J, Lammert A, Böttner A, et al, 2002 Circulating soluble leptin receptor and free leptin index during childhood, puberty, and adolescence. J Clin Endocrinol Metab 87: 4587-4594.

32. Yang G, Ge H, Boucher A, et al, 2004 Modulation of direct leptin signaling by soluble leptin receptor. Mol Endocrinol 18: 1354-1362.

33. Zastrow O, Seidel B, Kiess W, et al, 2003 The soluble leptin receptor is crucial for leptin action: evidence from clinical and experimental data. Int J Obes Relat Metab Disord 27: 1472-1478.

34. Heymsfield SB, Greenberg AS, Fujioka K, et al, 1999 Recombinant leptin for weight loss in obese and lean adults: a randomized, controlled, dose-escalation trial. JAMA 282: 1568-1575.

35. Takeda S, 2005 Central control of bone remodeling. Biochem Biophys Res Commun 328: 697-699.

36. Somasundar P, McFadden DW, Hileman SM, et al, 2004 Leptin is a growth factor in cancer. J Surg Res 116: 337-349.

37. Ciccone M, Vettor R, Pannacciulli N, et al, 2001 Plasma leptin is independently associated with the intimamedia thickness of the common carotid artery. Int $\mathbf{J}$ Obes Relat Metab Disord 25: 805-810.

38. Steppan CM, Lazar MA, 2004 The current biology of resistin. J Intern Med 255: 439-447.

39. Patel L, Buckels AC, Kinghorn IJ, et al, 2003 Resistin is expressed in human macrophages and directly regulated by PPAR gamma activators. Biochem Biophys Res Commun 300: 472-476.

40. Rajala MW, Qi Y, Patel HR, et al, 2004 Regulation of resistin expression and circulating levels in obesity, diabetes, and fasting. Diabetes 53: 1671-1679.

41. Rea R, Donnelly R, 2004 Resistin: an adipocyte-derived hormone. Has it a role in diabetes and obesity? Diabetes Obes Metab 6: 163-170.

42. Gerber M, Böttner A, Seidel B, et al, 2005 Serum resistin levels of obese and lean children and adolescents: biochemical analysis and clinical relevance. J Clin En- 
docrinol Metab (in press).

43. Conneely KN, Silander K, Scott LJ, et al, 2004 Variation in the resistin gene is associated with obesity and insulin-related phenotypes in Finnish subjects. Diabetologia 47: 1782-1788.

44. Fasshauer M, Paschke R, 2003 Regulation of adipocytokines and insulin resistance. Diabetologia 46: 15941603.

45. Banerjee RR, Rangwala SM, Shapiro JS, et al, 2004 Regulation of fasted blood glucose by resistin. Science 303: 1195-1198.

46. Reilly MP, Lehrke M, Wolfe ML, et al, 2005 Resistin is an inflammatory marker of atherosclerosis in humans. Circulation 111: 932-939.

47. Bokarewa M, Nagaev I, Dahlberg L, et al, 2005 Resistin, an adipokine with potent proinflammatory properties. J Immunol 174: 5789-5795.

48. Berg AH, Scherer PE, 2005 Adipose tissue, inflammation, and cardiovascular disease. Circ Res 96: 939-949.

49. Kubota N, Terauchi Y, Yamauchi T, et al, 2002 Disruption of adiponectin causes insulin resistance and neointimal formation. J Biol Chem 277: 25863-25866.

50. Maahs DM, Ogden LG, Kinney GL, et al, 2005 Low plasma adiponectin levels predict progression of coronary artery calcification. Circulation 111: 747-753.

51. Maeda N, Shimomura I, Kishida K, et al, 2002 Dietinduced insulin resistance in mice lacking adiponectin/ACRP30. Nat Med 8: 731-737.

52. Goldstein BJ, Scalia R, 2004 Adiponectin: A novel adipokine linking adipocytes and vascular function. J Clin Endocrinol Metab 89: 2563-2568.

53. Matsuzawa Y, 2005 Adiponectin: Identification, physiology and clinical relevance in metabolic and vascular disease. Atheroscler 6: Suppl: 7-14.

54. Brakenhielm E, Veitonmaki N, Cao R, et al, 2004 Adiponectin-induced antiangiogenesis and antitumor activity involve caspase-mediated endothelial cell apoptosis. Proc Natl Acad Sci U S A 101: 2476-2481.

55. Kadowaki T, Yamauchi T, 2005 Adiponectin and adiponectin receptors. Endocr Rev 26: 439-451.
56. Civitarese AE, Jenkinson CP, Richardson D, et al, 2004 Adiponectin receptors gene expression and insulin sensitivity in non-diabetic Mexican Americans with or without a family history of Type 2 diabetes. Diabetologia 47: 816-820.

57. Lihn AS, Pedersen SB, Richelsen B, 2005 Adiponectin: action, regulation and association to insulin sensitivity. Obes Rev 6: 13-21.

58. Fukuhara A, Matsuda M, Nishizawa M, et al, 2005 Visfatin: a protein secreted by visceral fat that mimics the effects of insulin. Science 307: 426-430.

59. Hug C, Lodish HF, 2005 Medicine. Visfatin: a new adipokine. Science 307: 366-367.

60. Boucher J, Masri B, Daviaud D, et al, 2005 Apelin, a newly identified adipokine up-regulated by insulin and obesity. Endocrinology 146: 1764-1771.

61. Komazawa N, Matsuda M, Kondoh G, et al, 2004 Enhanced insulin sensitivity, energy expenditure and thermogenesis in adipose-specific Pten suppression in mice. Nat Med 10: 1208-1215.

62. Liu YM, Moldes M, Bastard JP, et al, 2004 Adiponutrin: A new gene regulated by energy balance in human adipose tissue. J Clin Endocrinol Metab 89: 26842689.

63. Wolins NE, Quaynor BK, Skinner JR, et al, 2005 S312, Adipophilin, and TIP47 package lipid in adipocytes. J Biol Chem 280: 19146-19155.

64. Bao Y, Bing C, Hunter L, Jenkins JR, Wabitsch M, Trayhum P, 2005 Zinc-alpha2-glycoprotein, a lipid mobilizing factor, is expressed and secreted by human (SGBS) adipocytes. FEBS Lett 579: 41-47.

65. Finer N, 2002 Pharmacotherapy of obesity. Best Practice \& Research Clinical Endocrinology and Metabolism 16: 717-742.

66. Fontaine KR, Redden DT, Wang C, Westfall AO, Allison DB, 2003 Years of life lost due to obesity. JAMA 289: 187-193.

67. Fitzner K, Caputo N, Trendell W, French MV, Bondi MA, Jennings C, 2003 Recent tax changes may assist treatment of obesity. Manag Care Interface 16:47-51. 